\title{
SOEP
}

SOEPpapers

on Multidisciplinary Panel Data Research

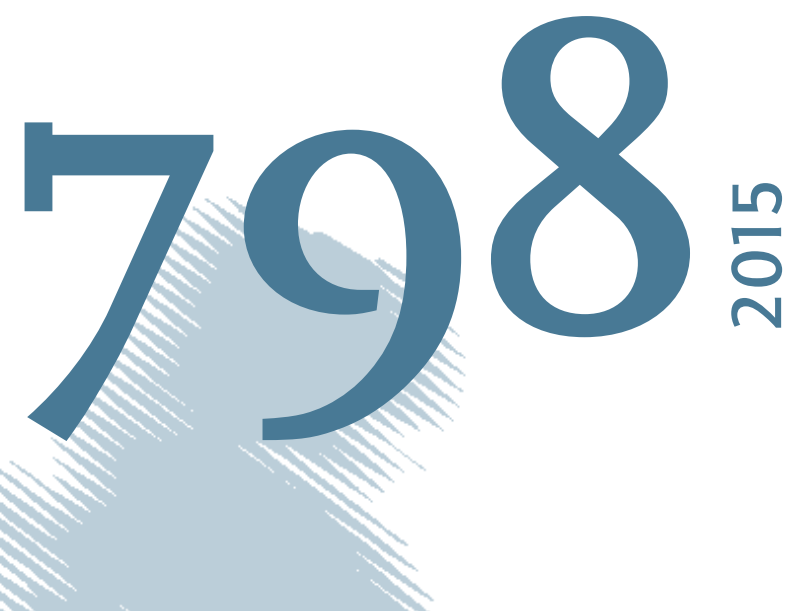

\section{Equality of Opportunity: East vs. West Germany}

Andreas Peichl and Martin Ungerer 
This series presents research findings based either directly on data from the German SocioEconomic Panel study (SOEP) or using SOEP data as part of an internationally comparable data set (e.g. CNEF, ECHP, LIS, LWS, CHER/PACO). SOEP is a truly multidisciplinary household panel study covering a wide range of social and behavioral sciences: economics, sociology, psychology, survey methodology, econometrics and applied statistics, educational science, political science, public health, behavioral genetics, demography, geography, and sport science.

The decision to publish a submission in SOEPpapers is made by a board of editors chosen by the DIW Berlin to represent the wide range of disciplines covered by SOEP. There is no external referee process and papers are either accepted or rejected without revision. Papers appear in this series as works in progress and may also appear elsewhere. They often represent preliminary studies and are circulated to encourage discussion. Citation of such a paper should account for its provisional character. A revised version may be requested from the author directly.

Any opinions expressed in this series are those of the author(s) and not those of DIW Berlin. Research disseminated by DIW Berlin may include views on public policy issues, but the institute itself takes no institutional policy positions.

The SOEPpapers are available at

http://www.diw.de/soeppapers

\section{Editors:}

Jan Goebel (Spatial Economics)

Martin Kroh (Political Science, Survey Methodology)

Carsten Schröder (Public Economics)

Jürgen Schupp (Sociology)

Conchita D'Ambrosio (Public Economics)

Denis Gerstorf (Psychology, DIW Research Director)

Elke Holst (Gender Studies, DIW Research Director)

Frauke Kreuter (Survey Methodology, DIW Research Fellow)

Frieder R. Lang (Psychology, DIW Research Fellow)

Jörg-Peter Schräpler (Survey Methodology, DIW Research Fellow)

Thomas Siedler (Empirical Economics)

C. Katharina Spieß (Education and Family Economics)

Gert G. Wagner (Social Sciences)

ISSN: 1864-6689 (online)

German Socio-Economic Panel (SOEP)

DIW Berlin

Mohrenstrasse 58

10117 Berlin, Germany

Contact: Uta Rahmann | soeppapers@diw.de

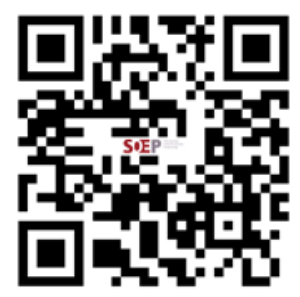




\title{
Equality of Opportunity: East vs. West Germany
}

\author{
Andreas Peichl and Martin Ungerer*
}

October 12, 2015

\begin{abstract}
:
The case of German reunification has been subject to extensive research on earnings inequality and labor market integration. However, little is known about the development of equality of opportunity (EOp) in East and West Germany after 1990. Using German micro data, we empirically analyze how circumstances beyond the sphere of individual control explain inequality in East and West Germany. Our results suggest that equal opportunities in Germany have grown since reunification. Interestingly, EOp is larger in East than in West Germany.
\end{abstract}

JEL Codes: D63, H2, J62, J7

Keywords: Equality of Opportunity; Earnings Inequality; Germany; Family Background

\footnotetext{
* Andreas Peichl (peichl@zew.de) is affiliated to ZEW, University of Mannheim, IZA, and CESifo. Martin Ungerer (ungerer@zew.de) is affiliated to ZEW and University of Cologne. Corresponding author: Andreas Peichl, ZEW Mannheim, L7, 1, 68161 Mannheim, Germany.
} 


\section{Introduction}

The fall of the Berlin Wall and the opening of the intra-German border motivated politicians to talk about the prospect of "blossoming landscapes" providing East German individuals with many new opportunities. However, 25 years later, unemployment is still much higher in the East which questions this promising economic perspective. The aim of this paper is to analyze equality of opportunity (EOp) in East and West Germany.

Prior to German reunification, West Germany was characterized by a larger middle class, with a classic role model of the male breadwinner and relatively higher importance of family background, e.g. with regards to educational decisions (Rosenfeld et al. 2004). In contrast, the former German Democratic Republic featured higher full-time employment rates of women as well as an intensive child care system. Furthermore, there was much less dependence on parental resources to get access to higher education. In such a socialist society, social and family background are expected to be of less importance for children's outcomes. In the course of German reunification, this system was abolished within a short period of time. Essentially, the West German institutional structure was implemented in East Germany in the process of reunification (ZUMA. Abteilung Soziale Indikatoren 2004). While there has been extensive research on earnings inequality and labor market integration after German reunification, little is known about EOp in West versus East Germany $!^{1}$

While the traditional notion of equality of outcomes refers to an equal distribution of economic outcomes (e.g. consumption or income), the EOp theory, in contrast, is interested in the sources of inequality and separates the influences on the outcomes of an individual into circumstances and effort 2 Circumstances are defined as all factors beyond the sphere of individual control, for which society deems individuals should not be held responsible - such as parental education or gender. Effort, on the other hand, comprises all choices within individual responsibility for which society holds the individual (partially) accountable, e.g. schooling or labor supply decisions. Income inequalities due to differences in effort are deemed acceptable, whereas inequalities due to endowed characteristics are not.

The aim of this paper is straightforward. We estimate inequality of opportunity (IOp) following the approach suggested by Ferreira and Gignoux (2011) and Niehues and Peichl (2013) for Germany as a whole as well as separately for East and West

\footnotetext{
${ }^{1}$ Trappe and Sørensen (2005) analyze labor market participation rates and job opportunities for men and women in both parts of Germany after 1990. Their findings suggest remarkable differences in the labor market structure at the time of reunification. Despite some trend of convergence, structural differences remain.

${ }^{2}$ See Roemer (1998), Van de Gaer (1993) and Fleurbaey (1995) for seminal contributions and Roemer and Trannoy (2013) for a recent survey.
} 
Germany. This allows us to analyze whether opportunities differ between the two parts of the country. We employ a rich panel data set for the years 1991-2011 and are therefore able to look at potential convergence over time.

Our results suggest that equal opportunities in Germany have grown since German reunification. What is remarkable: The chances to obtain a higher income through personal effort are significantly higher in Eastern Germany than in the West. One reason for this finding is the relatively strong, established middle class in West Germany resulting in lower mobility.

\section{Conceptual Framework and Methodology}

We follow standard practice to estimate EOp. In accordance with Roemer (1998), we distinguish between two generic determinants of outcome $w_{i s}$ of individual $i$ at time point $s$. First, circumstances $C_{i}$ are characteristics outside individual control (think of race, gender, family background) and hence a source of inequitable inequalities in outcomes. Second, effort $E_{i s}$ is representing all factors affecting earnings that are assumed to be the result of personal responsibility. Following Ferreira and Gignoux (2011), we assume that the outcome variable of interest depends both on exogenous, time-invariant circumstances $C_{i}$ as well as time-varying personal effort $E_{i s}$, which can be shaped by $C_{i}$.

We employ the ex-ante approach of EOp and partition the population of agents $i \in$ $\{1, \ldots N\}$ into a set of disjunct types $\Pi=\left\{T_{1}, T_{2}, \ldots T_{k}\right\}$, i.e., subgroups of the population that are homogeneous in terms of their circumstances. The income distribution within a type is a representation of the opportunity set which can be achieved for individuals with the same circumstances $C_{i}$ by exerting different degrees of effort. Perfect EOp is achieved if the mean advantage levels $\mu$ are identical across types, i.e., $\mu^{k}(w)=$ $\mu^{l}(w), \forall l, k \mid T_{k}, T_{l} \in \Pi$. Measuring IOp thus means capturing the extent to which $\mu^{k}(w) \neq \mu^{l}(w)$, for $k \neq l$. To compute a measure of IOp, Checchi and Peragine (2010) suggest constructing a hypothetical smoothed distribution: $\widetilde{\mu}_{i}^{k}(w)$, which is obtained when each individual outcome $w_{i}^{k}$ is replaced by $\mu^{k}(w)$, the group-specific mean for each type.

Based on this smoothed distribution, we compute for any (scale invariant) inequality index $I$ the absolute inequality of opportunity level (IOL) $\theta_{a}=I\left(\left\{\widetilde{\mu}_{i}^{k}\right\}\right)$. The relative share of total inequality that can be attributed to circumstances, i.e. the inequality of

opportunity ratio (IOR) is defined as $\theta_{r}=\frac{I\left(\left\{\widetilde{\mu}_{i}^{k}\right\}\right)}{I(w)}$. As Niehues and Peichl (2013), we use the mean log deviation (MLD) as inequality measure $I$ since it is the only inequality measure that respects all necessary axioms for this decomposition analysis.

In our empirical estimation approach, we use the same parametric specification as 
Niehues and Peichl (2013) to estimate IOp. ${ }^{3}$ Relying on a parametric approach allows us to estimate the impact of numerous circumstance variables even in the presence of small samples - which, unfortunately, is the case in the data that we use for our empirical analysis. 4 The empirical specifications for individual $i$ in year $s$ reads:

$$
\begin{aligned}
\ln w_{i s} & =\alpha C_{i}+\beta E_{i s}+u_{i s} \\
E_{i s} & =\kappa C_{i}+v_{i s} .
\end{aligned}
$$

Equation (1) represents the direct effect of circumstances on income while equation (2) models the indirect effect of circumstances on income through effort. Since it is unlikely that we will observe all relevant circumstance and effort variables that shape individuals' outcomes, estimating this model will likely yield biased estimates. However, in order to compute IOp shares, it is not necessary to estimate the structural model and to derive causal relationships. By substituting the effort equation (2) into the earnings equation (1), we obtain the following reduced-form relationship:

$$
\ln w_{i s}=\underbrace{(\alpha+\beta \kappa)}_{\psi} C_{i}+\underbrace{\beta v_{i s}+u_{i s}}_{\eta_{i s}} .
$$

This reduced-form equation can be estimated by OLS to derive the fraction of variance which is explained by circumstances. Including all observed circumstances $C^{K}$ in equation (3), the estimates $\widehat{\psi}$ measure the overall effect of observed circumstances on labor earnings, combining both the direct and indirect effects. Based on this, we can construct a parametric estimate of the smoothed distribution:

$$
\widetilde{\mu}=\exp \left[\widehat{\psi} C_{i}^{K}+\sigma^{2} / 2\right]
$$

As we replace earnings outcomes by their predictions $\left(\sigma^{2}\right.$ is the estimated residual variance in the earnings equation), all individuals with the same circumstances necessarily have the same advantage levels. Thus, in the case of absolute EOp, i.e.

\footnotetext{
${ }^{3}$ In empirical estimations of EOp, it is impossible to observe all characteristics that constitute individual's circumstances (e.g. innate talent or ability). Hence, existing estimates of IOp are only lower bound estimates of the true share of unfair inequalities due to circumstances (Ferreira and Gignoux (2011)). An exception is Niehues and Peichl (2013) who also suggest an upper bound estimator in addition to the lower bound estimator we are employing here.

${ }^{4}$ In contrast, non-parametric methods avoid the arbitrary choice of a functional form on the relationship between outcome, circumstances and effort (e.g. Lefranc et al. (2008), Ferreira and Gignoux (2011) or Aaberge et al. (2011)). However, this approach has the drawback that considering more than one circumstance variable is difficult due to practical reasons in the presence of small cell sizes for various types which is usually the case in survey data. Access to large-scale administrative panel data with information on circumstances (family background), which is not available in Germany, would allow to estimate IOp also non-parametrically.
} 
no income differences due to (observed) circumstances $C_{i}^{K}$, all predicted earning levels would be identical. Consequently, IOp can then be measured as the inequality of these counterfactual earnings levels, where differences are only due to differences in circumstances.

\section{Data}

We use the latest version of the German Socio-Economic Panel (SOEP) for our estimations ${ }^{5}$. The SOEP is a representative panel study of households and individuals in Germany that has been conducted annually since 1984 ${ }^{6}$ For our analysis, we use information for the years 1991-2011, i.e. the available years after German reunification.

In line with the previous literature, the units of our analysis are working age individuals (aged 25-55) with non-missing data on parental background. The dependent variables are log real (gross or net) labor earnings, adjusted by consumer prices indices. Inequality measures are based on the corresponding absolute levels of earnings.

As circumstance variables, we include gender, a dummy whether the individual was born in a foreign country, categorical variables of the occupation and education of the father, the degree of urbanization of the place where the individual was born as well as the height and year of birth of the individual. We include a dummy if the individual was born in East Germany. Summary statistics are reported in table A.2 in the appendix.

\section{Empirical results}

We begin our analysis by regressing the log earnings for each year on all available circumstance variables which are expected to have an impact on labor earnings (equation 3 . results available upon request). Using the full sample, we find the well-known gender gap in earnings. Although it is slightly declining over time, women have significantly lower wages compared to men. Being an immigrant or born in East Germany before 1989 yields a negative impact on wages. Individuals with highly educated fathers or parents working as civil servants have higher wages compared to blue-collar workers or self-employed parents. Living in larger cities also is associated with higher wages compared to living in the countryside. Higher educational attainment of the father leads to higher wages. The main drivers of the observed differences between East and

\footnotetext{
${ }^{5}$ Socio-Economic Panel (SOEP) (2013)

${ }^{6} \mathrm{~A}$ detailed overview of the SOEP is provided by Wagner et al. (2007). Issues concerning sampling and weighting methods or the imputation of information in case of item or unit non-response is well documented by the SOEP Service Group.
} 
West Germany are fathers education and occupation, gender as well as migration background. Moreover, mean earnings are higher for West Germany compared to the East. However, gross earnings' inequality in East Germany is considerably lower compared to the West - see Figure A.1 in the Online Appendix. In addition, there is an upward trend in earnings inequality in both, East and West Germany. As the trend is stronger for the East, we see a convergence over time.

Figure 1 shows IOp in levels for East and West Germany in gross and net earnings. IOL is always lower in East compared to West Germany. However, there is no clear trend visible for either region and the levels remained fairly constant over the whole period. Furthermore, the differences between net and gross income are negligible. That is, redistribution through the tax benefit system does not affect inequality of opportunity - neither in East nor in West Germany $!^{7}$ Since the values of IOL are not so easy to compare, we further look at IOR as a relative measure.

Figure 2 shows the IOR, i.e. the ratio between IOL and total inequality, for East and West Germany as well as for Germany as a whole in gross and net earnings. IOR in East Germany is generally lower compared to West Germany, with values of $15.2 \%$ and $36.1 \%$ in 1991 and $13.0 \%$ and $27.6 \%$ in 2011, respectively. That is, while in West Germany roughly a third of total inequality is due to exogenous circumstances, this value is about one sixth in the East. However, while there is a decreasing trend in IOR in West Germany (with a small spike in 2008)), we find mixed results for East Germany. Here, IOR is increasing after the German reunification, with a peak in 1994 of $23.6 \%$ for gross income. This increase may partly be attributed to the process of convergence between the two formerly separated parts of Germany. After 1998, IOR is decreasing until 2001, slightly increasing until 2008 and then decreasing. IOR is slightly larger for both East and West Germany when looking at net earnings, suggesting that the tax benefit systems slightly worsens opportunities 8 The decrease in IOR is mainly driven by rising earnings inequality, as IOL stayed rather constant over time.

\section{Conclusion}

Our results show that, equality of opportunity, i.e. the chances to gain a higher income through personal effort, to live a success story leading, at best, from rags to riches, is smaller in West relative to East Germany. There are several reasons for the East-West disparities. First, the gender wage gap is less pronounced in East Germany than in the

\footnotetext{
${ }^{7}$ One reason for this is that tagging, i.e. the use of exogenous circumstances to determine tax liabilities and benefit eligibility, is usually not explicitly used in existing tax benefit systems due to anti-discrimination laws.

${ }^{8}$ This is not surprising given that the tax benefit system reduces income inequality levels but not IOL.
} 
West, which has a positive effect on equal opportunities. Second, parents' education, income and socio-economic status have a greater impact on children's education and income in West Germany due to a stronger established middle class resulting in lower intergenerational mobility. Another important possible factor is the better availability of (full-day) childcare in East Germany leading to a higher labor force attachment of women. The overall decrease in IOR is mainly due to an increase in earnings inequality, as the level of IOp stayed rather constant. It is one of the major policy challenges in Germany to increase equal opportunities by introducing reforms to the education system, expanding childcare and improving the integration of migrants into society. 


\section{References}

Aaberge, R., Mogstad, M. and Peragine, V. (2011). Measuring long-term inequality of opportunity, Journal of Public Economics 95(3): 193-204.

Checchi, D. and Peragine, V. (2010). Inequality of opportunity in Italy, The Journal of Economic Inequality 8(4): 429-450.

Ferreira, F. H. and Gignoux, J. (2011). The measurement of inequality of opportunity: Theory and an application to Latin America, Review of Income and Wealth 57(4): 622-657.

Fleurbaey, M. (1995). Three solutions for the compensation problem, Journal of Economic Theory 65(2): 505-521.

Lefranc, A., Pistolesi, N. and Trannoy, A. (2008). Inequality of opportunities vs. inequality of outcomes: Are western societies all alike?, Review of Income and Wealth 54(4): 513-546.

Niehues, J. and Peichl, A. (2013). Upper bounds of inequality of opportunity: theory and evidence for Germany and the US, Social Choice and Welfare pp. 1-27.

Roemer, J. (1998). Equality of Opportunity, Harvard University Press.

Roemer, J. and Trannoy, A. (2013). Equality of opportunity, Cowles Foundation Discussion Paper No. 1921, forthcoming in Handbook of Income Distribution.

Rosenfeld, R. A., Trappe, H. and Gornick, J. C. (2004). Gender and work in Germany: Before and after reunification, Annual Review of Sociology pp. 103-124.

Socio-Economic Panel (SOEP) (2013). data for years 1984-2012. version 29, SOEP, 2013, doi:10.5684/soep.v29.

Trappe, H. and Sørensen, A. (2005). Economic relations between women and their partners: An East-West-German comparison after reunification, DIW Discussion Paper 544.

Van de Gaer, D. (1993). Equality of opportunity and investment in human capital, Working paper, KU Leuven.

Wagner, G. G., Frick, J. R. and Schupp, J. (2007). The German Socio-Economic Panel Study (SOEP)-evolution, scope and enhancements, Schmollers Jahrbuch 127 no. 1: 139 - 169 . 
ZUMA. Abteilung Soziale Indikatoren (2004). System sozialer Indikatoren für die Bundesrepublik: Schlüsselindikatoren 1950-2003. 


\section{Figures}

Figure 1: IOp (MLD) in levels (IOL) for annual income - gross vs. net
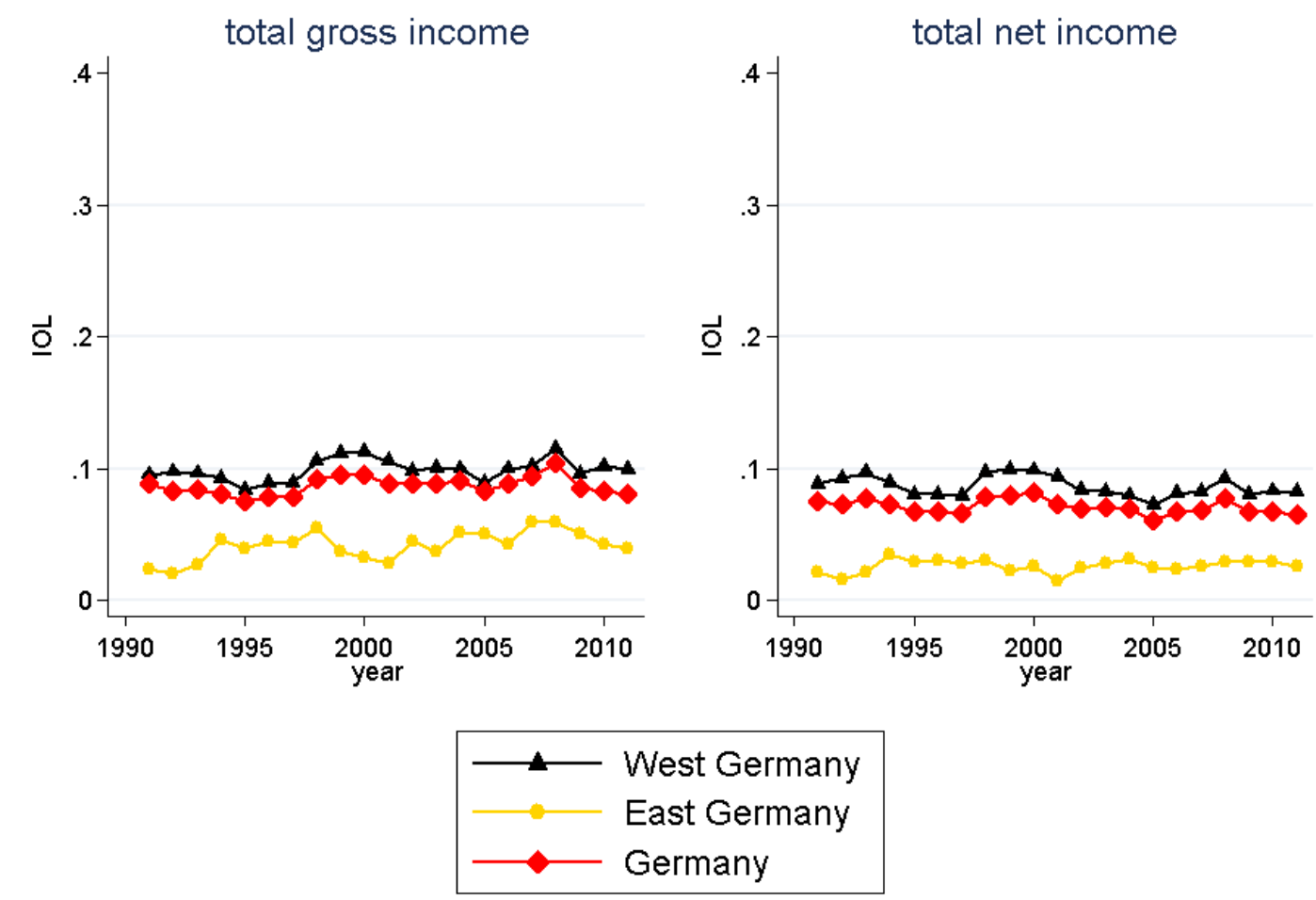

Source: Authors calculation based on SOEP 
Figure 2: IOR (IOL in relation to total inequality) for annual income - gross vs. net
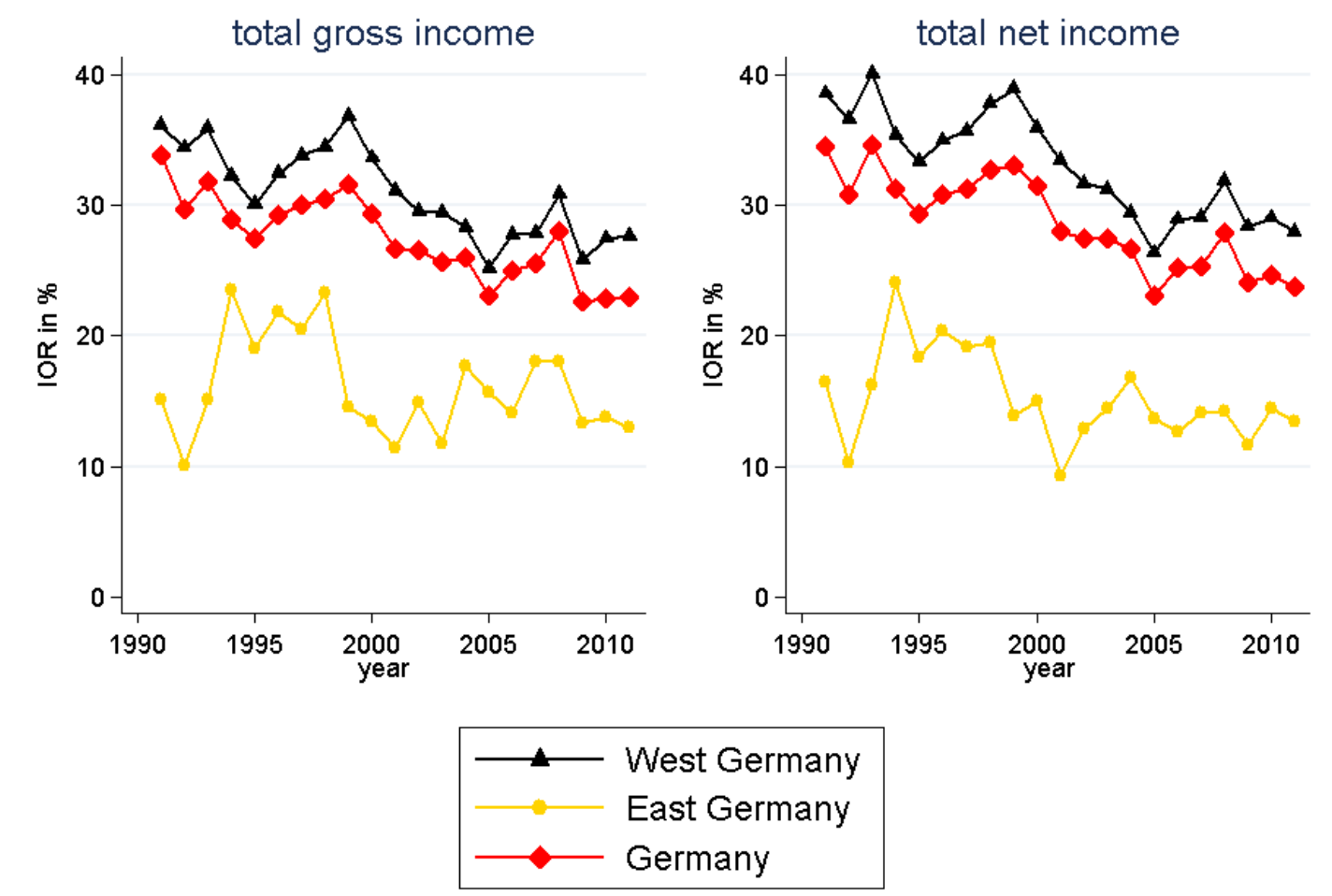

Source: Authors calculation based on SOEP

\section{A Online Appendix}

Table A.1: Descriptive Statistics for Basic Variables

\begin{tabular}{lcccc}
\hline Variable & Mean & Sd & Min & Max \\
\hline Real Gross Earnings & 29490.88 & 23164.12 & 25 & 1269829 \\
Real Net Earnings & 21707.94 & 14993.4 & 22.15 & 748994.1 \\
Gender & .46 & .5 & 0 & 1 \\
Ethnic & .06 & .24 & 0 & 1 \\
East Germany & .19 & .39 & 0 & 1 \\
\hline
\end{tabular}


Table A.2: Descriptive Statistics for IOp Measures

\begin{tabular}{cccccc}
\hline Year & Observations & MLD gross & MLD net & IOR gross & IOR net \\
\hline 1991 & 2893 & .26 & .22 & 33.81 & 34.53 \\
1992 & 2959 & .28 & .24 & 29.66 & 30.83 \\
1993 & 2964 & .26 & .22 & 31.85 & 34.54 \\
1994 & 2986 & .28 & .23 & 28.94 & 31.25 \\
1995 & 3017 & .27 & .23 & 27.48 & 29.33 \\
1996 & 3025 & .27 & .22 & 29.22 & 30.77 \\
1997 & 3398 & .26 & .21 & 30.05 & 31.27 \\
1998 & 3531 & .3 & .24 & 30.49 & 32.69 \\
1999 & 6322 & .3 & .24 & 31.54 & 33.07 \\
2000 & 6446 & .33 & .26 & 29.35 & 31.43 \\
2001 & 7483 & .33 & .26 & 26.62 & 27.96 \\
2002 & 7275 & .33 & .25 & 26.57 & 27.46 \\
2003 & 7038 & .34 & .26 & 25.6 & 27.39 \\
2004 & 6642 & .35 & .26 & 26.01 & 26.61 \\
2005 & 6820 & .36 & .26 & 23.12 & 23.1 \\
2006 & 6558 & .36 & .27 & 24.92 & 25.16 \\
2007 & 6229 & .37 & .27 & 25.52 & 25.31 \\
2008 & 5746 & .37 & .28 & 27.95 & 27.92 \\
2009 & 5264 & .38 & .28 & 22.57 & 24.1 \\
2010 & 5291 & .36 & .27 & 22.8 & 24.68 \\
2011 & 4911 & .35 & .27 & 22.94 & 23.77 \\
\hline
\end{tabular}


Figure A.1: MLD for annual income - gross vs. net
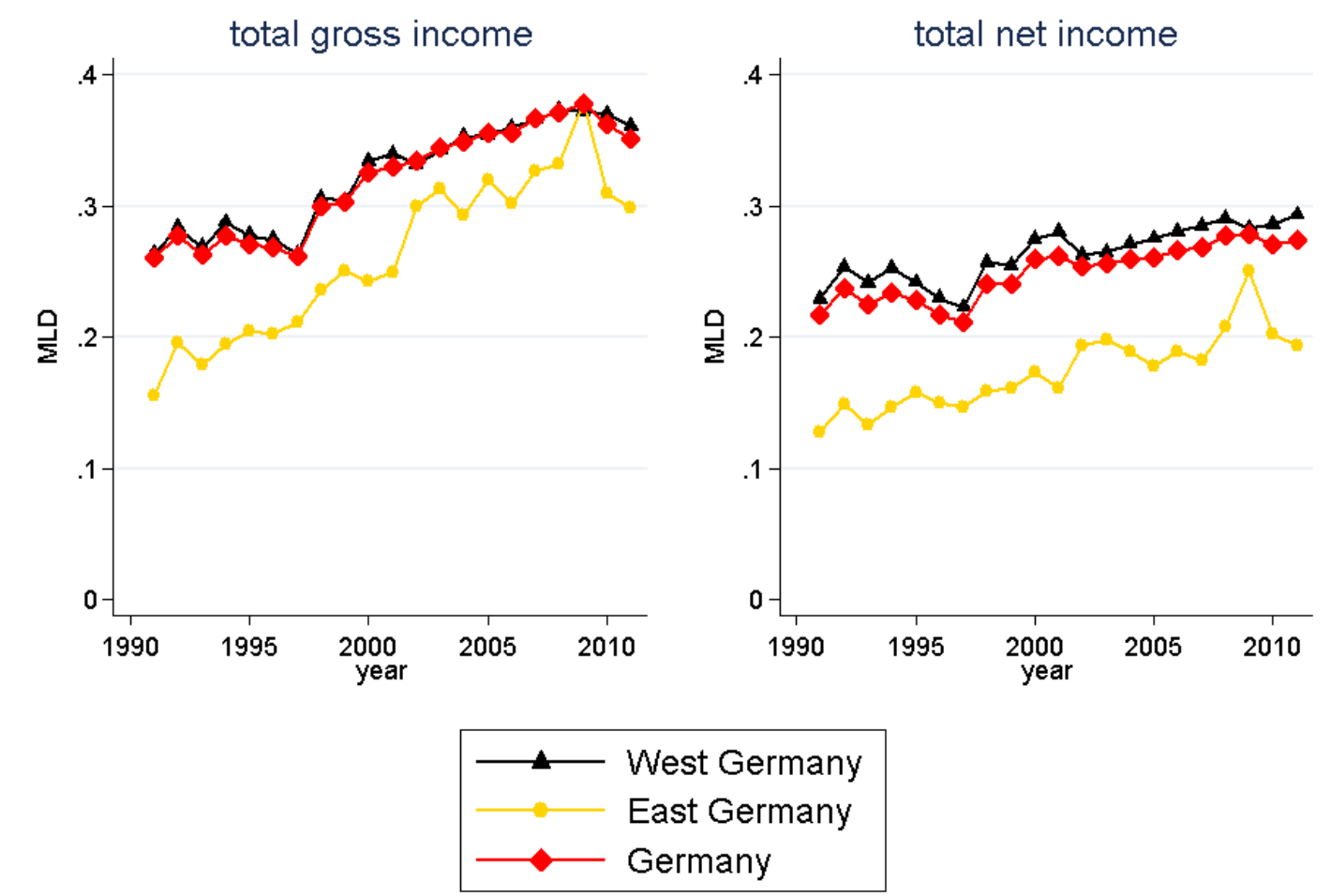

Source: Authors calculation based on SOEP 